\title{
Emotionalism Following Brain Damage
}

\author{
PETER ALLMAN \\ Chest, Heart and Stroke Association Research Fellow, University Department of Psychiatry, Warneford \\ Hospital, Oxford, OX377X, England
}

\begin{abstract}
Emotionalism is an heightened tendency to cry, or more rarely, laugh. It is commonly associated with brain damage and is often distressing to both patients and carers. Emotionalism is easily confused with depression, and when severe it can interfere with treatment. The aetiology is poorly understood but its response to drugs with different modes of action suggests that there is more than one underlying mechanism. When the components of emotionalism are studied separately a wide range is observed and they combine in a more complex and varied way than commonly held stereotyped views suggest. Most patients with emotionalism are helped by simple education and reassurance. Some severe cases respond dramatically to tricyclic antidepressants, levodopa or fluoxetine.
\end{abstract}

\section{Introduction}

Crying is a complex emotional and behavioural state which arises in a wide variety of both commonplace and pathological conditions. People may cry when watching a sad film, when bereaved, or as part of an affective disorder. Tearfulness can also accompany physical illness and it has long been known that there is a particular association between brain damage and a heightened tendency towards crying (and laughing) (Darwin, 1872). This emotionalism can be distressing to both patients and carers and for some it is the most disturbing of all the physical or psychological sequelae. Patients do not often seek advice about emotionalism even when it is persistent and distressing, and it is common for hospital staff to be unaware of the problem. When it is recognized it is often misconstrued as a form of communication; a way of showing frustration; or a feature of an affective disorder. Treatments such as speech therapy or physiotherapy can be difficult or impossible when crying is particularly frequent (Brookshire, 1970).

\section{Nomenclature}

The terminology used in describing this phenomenon is confused (Allman, 1989). Terms such as pathological crying, emotional lability, emotional incontinence, forced crying and pseudobulbar emotionality are often used synonymously. Alternatively, they are used to refer to what are thought to be different subtypes (Poeck, 1969). The term pathological crying wrongly implies a division between one form of crying that is pathological and another that is not. Emotional lability is unsuitable since it is a term widely 
used in psychiatry to refer to phenomena quite unlike the one under consideration. The term emotionalism seems the most satisfactory (Allman, 1989).

\section{Definition}

Emotionalism can be defined as a heightened tendency to cry (or rarely laugh) such that crying occurs more frequently, more easily, more vigorously, or in circumstances that previously would have been out of character. For the purposes of research it may be necessary to define a subgroup in terms of frequency and duration. Criteria such as lack of warning, absence of control, rapidity of onset, and inappropriateness should be avoided because they are difficult to judge and are unnecessarily restrictive.

\section{Epidemiology}

The prevalence of emotionalism (defined in terms of increased frequency of crying that is sudden and uncontrollable) in a community sample of stroke patients was found to be $15 \%$ at 1 month, $21 \%$ at 5 months and $11 \%$ at 1 year (House et al., 1989). The rate is likely to be higher in those admitted to hospital. Half of a highly selected group of patients with amyotrophic lateral sclerosis reported bouts of "unwanted laughter or crying" (Gallagher, 1989).

\section{Natural history}

Following stroke, most patients who develop emotionalism do so within the first month and the frequency and intensity of the crying tends to gradually diminish over the first year (House et al., 1989). Only a small proportion have troublesome emotionalism that persists for months or years.

\section{Aetiology}

Emotionalism is not exclusively linked with a lesion of any particular brain structure or pathway. Many patients with emotionalism have one or more lesions affecting the cortico-bulbar pathways and although it is classically associated with lesions of the brain stem (Wilson, 1924), emotionalism has been described in patients with circumscribed unilateral hemispheric lesions (Ross and Stewart, 1987). In stroke patients emotionalism is statistically associated with left frontal lesions and large lesions (House et al., 1989). Given that it is also associated with cognitive impairment it may be that the extent of brain damage is more important than its location (House et al., 1989).

Clues to the neurochemical changes associated with emotionalism can be found in its response to drugs with completely different modes of action such 
as levodopa (dopaminergic) (Udaka et al., 1984) and fluoxetine (serotonergic) (Sloan et al., 1991). It is therefore likely that there is more than one underlying mechanism.

Emotionalism has been described in association with a wide variety of brain pathologies particularly stroke (House et al., 1989), multiple sclerosis (Surridge, 1969), motor neurone disease (Gallagher, 1989), and cerebral tumour (Wilson, 1924). Crying or laughing occasionally occurs as part of the ictus in epilepsy (dacrystic and gelastic epilepsy respectively) (Offen $e t$ al., 1976; Sethi and Rao, 1976) and even less commonly as a dramatic presenting feature in patients with brain stem pathology (Fere, 1903).

Following stroke, patients with emotionalism have more symptoms of mood disorder and more diagnosable psychiatric disorder (only at 6 months) (House et al., 1989). This does not imply a direct link between emotionalism and mood disorder and it is worth emphasizing that emotionalism is also seen in patients with few psychological symptoms. It is possible that those with emotionalism are also more physically disabled but this remains to be established. The influence of personality factors, adjustment or grief is not known. When talking to patients who cry easily following stroke some give the impression that they are less bothered about normal social constraints on displays of emotion. Also, situations with an emotive content (for example, a visit from a grandchild) become invested with more meaning and are consequently more potent in provoking crying than they were before the illness.

\section{Assessment}

For the purposes of research a semi-structured interview with the patient and their carer is the best method of gaining reliable information on each of the main components of emotionalism (Allman et al., 1991a). Trained interviewers can estimate the global severity of emotionalism with substantial reliability (Allman et al., 1991a). For treatment studies some patients or their carers can keep simple diaries of the frequency of crying (Schiffer et al., 1985 ) and it is sometimes possible to devise interview-based provocation tests in those with severe emotionalism. In the clinical context it is important to ask about crying in all patients with brain damage since most do not volunteer the symptom even when it is a problem. Since it is possible for emotionalism to occur independently of abnormal adjustment or depressive disorders the frequency of crying should not be taken into account when making these diagnoses.

\section{Clinical features}

When representative samples are studied a wide range of behaviour is observed. Crying is much more common than laughing and when crying and laughing occur in the same patient the episodes are usually distinct but occasionally crying merges imperceptibly with laughing. Mild emotionalism 
is manifest by brief episodes in which the patient "wells up" and appears close to tears. The facial expression turns to sorrow, there is a haltering of the voice, the lips tremble, and tears come to the eyes. Severe emotionalism is characterized by dramatic and rapidly evolving changes in facial expression, breathing, and posture. The expression is one of anguish in which the eyes are tightly closed and the mouth is contorted. Vigorous sobbing shakes the whole body and the patient wails or repeats stereotyped phrases. Some episodes are short lived and end abruptly within 30 seconds whilst others are prolonged and wax and wane over 10-15 minutes. Very rarely patients present with violent paroxysms of crying or laughing which continue for many hours. There appears to be a continuum of behaviour between these extremes.

The components of emotionalism have been described in a series of 30 stroke patients (Allman et al., 1991b). The range of frequency of crying was 1300 times per month (median 15). Nearly all had cried much more frequently or more easily following the stroke and over a third had cried more than once or twice per day. Complete lack of warning was uncommon and most patients $(83 \%)$ were able to tell when they were about to cry. The majority had some degree of control over the crying with only $17 \%$ having no control. The inter-personal context in which the crying occurred was limited to one or two circumscribed contexts in a quarter of patients (for example, crying only when asked about the symptom itself). Half cried in two or more social situations but the crying clearly remained constrained by the context. In a quarter the crying was independent of the social context with the behaviour occurring in the presence of complete strangers as well as with family and friends. The most common precipitants were: thoughts $(66 \%)$ (for example, about the family or about the illness and its consequences); kind gestures or expression of sympathy $(53 \%)$; and visitors arriving or departing $(37 \%)$. Other precipitants were: inability to perform a task; watching television (particularly news reports of tragedies and scenes of children suffering); disagreements; and listening to music. Five patients $(17 \%)$ reported spontaneous episodes for which no precipitant was identified. None of the patients cried in response to non-emotive stimuli. Five patients reported no change in mood as they cried but over half described feeling sad or miserable when crying. A quarter were unable to adequately describe their mood when crying.

Poeck (1969) has defined clinical subtypes and makes a distinction between pathological crying and emotional lability. Pathological crying is characterized by: response to non-specific stimuli (for example, a noise in the room); a lack of relationship between affective change and observed expression (i.e. crying without feeling sad); absence of voluntary control over the extent or duration of the facial expressions; and absence of a corresponding change in mood lasting beyond the crying. Emotional lability is described as a contextually appropriate and controllable response accompanied by an alteration in mood. It is often difficult to fit individual patients into these categories (Allman et al., 1990). In the study of 30 patients referred to above none fulfilled all of Poeck's criteria for pathological crying 
and no distinct subtypes of crying were identified (Allman et al., 1991b). The components of crying combined in a more complex and varied way than commonly held stereotyped views would suggest.

\section{Treatment}

Simple education and advice is all that is required for the majority of patients and carers. Some believe that they are going mad or that they have become weak willed, stupid or childlike so it is useful to ask patients about their understanding of the problem and offer alternative explanations. Most will benefit from knowing that the symptom is common and that it tends to improve with time. A useful parallel can be drawn between reduced control over the affected limbs and reduced control over the expression of the emotions. Carers should be encouraged to adopt a consistent approach and avoid inadvertently promoting the behaviour by automatically consoling the patient. Therapists in rehabilitation can agree with the patient that they will pause until the episode is over before continuing with the treatment. The place of specific psychological interventions has not been evaluated and there is only one report of the successful application of behaviour therapy in a patient with emotionalism and multiple sclerosis (Brookshire, 1970).

A small number of patients with emotionalism will be willing to try drug treatment. Uncontrolled trials show that antidepressant drugs and levodopa are effective in treating emotionalism in some patients (Lawson and MacLeod, 1969; Udaka et al., 1984; Sloan et al., 1991). Phenobarbitone and thioridazine have been tried but were ineffective (Lawson and MacLeod, 1969). Relatively small doses of imipramine $(30-60 \mathrm{mg})$ were used to treat severe emotionalism in seven patients with bilateral strokes; in four the response was complete and occurred within the first week, a further three patients responded but not completely (Lawson and MacLeod, 1969). A number of patients relapsed within 1 week of stopping treatment. Levodopa $(0.6-1.5 \mathrm{~g})$ produced a complete response within 5 days in 10 out of 25 patients with emotionalism following stroke (Udaka et al., 1984). Fluoxetine (a specific 5-hydroxytryptamine re-uptake blocker) produced a marked and rapid improvement in six stroke patients with emotionalism (Sloan et al., 1991). In a small double-blind placebo crossover study amitriptyline (50-75 mg) produced dramatic and significant improvement in emotionalism in eight out of 12 patients with multiple sclerosis (Schiffer et al., 1985). The responders had more severe emotionalism than non-responders.

Treatment trials with large numbers of patients are required before the proper place of drug treatment can be established. Given that there may be biological subtypes of emotionalism and that tricyclic antidepressants affect a wide range of neurotransmitter systems a trial of amitriptyline or imipramine in small doses $(50 \mathrm{mg})$ seems a reasonable first step. In patients with cardiovascular disease or in the elderly drugs such as dothiepin may be better tolerated. Levodopa and the newer 5HT re-uptake blockers are then available as reserves. 


\section{Acknowledgements}

I am grateful to Dr Tony Hope, Dr Dereck Wade, Dr Allan House and Dr Christopher Fairburn for helping with my research and to The Wellcome Trust and The Chest, Heart and Stroke Association for funding.

\section{References}

Allman, P. (1989). Crying and laughing after brain damage: a confused nomenclature. Journal of Neurology, Neurosurgery and Psychiatry, 52, 1439-1440.

Allman, P., Hope, R. A. and Fairburn, C. G. (1990). Emotionalism following brain damage: A complex phenomenon. Postgraduate Medical fournal, 66, 818-821.

Allman, P., Hope, R. A., Marshall, M. and Fairburn, C. G. (1991a). A semi-structured interview for the assessment of emotionalism. Submitted for publication.

Allman, P., Hope, R.A. and Fairburn, C. G. (1991b). Emotionalism following brain damage: A report on 30 cases. Submitted for publication.

Brookshire, R.H. (1970). Control of involuntary crying behaviour emitted by a multiple sclerosis patient. Fournal of Communication Disorders, 3, 171-176.

Darwin, G. (1872). "The Expression of the Emotions in Man and Animals." John Murray, London.

Fere, M. C. (1903). Le fou rire prodromique. Review Neurologique, 11, 353-358.

Gallagher, J. P. (1989). Pathological laughter and crying in amyotrophic lateral sclerosis: a search for their origin. Acta Neurologica Scandinavica, 80(2), 114-117.

House, A., Dennis, M., Molyneux, A., Warlow, C. and Hawton, K. (1989). Emotionalism after stroke. British Medical Fournal, 298, 991-994.

Lawson, I. R. and MacLeod, R. D. M. (1969). The use of imipramine and other psychotropic drugs in organic emotionalism. British Fournal of Psychiatry, 115, 281-285.

Offen, M. L., Davidoff, R. A., Troost, B. T. and Richey, E. T. (1976). Dacrystic epilepsy. Fournal of Neurology, Neurosurgery and Psychiatry, 39, 829-834.

Poeck, K. (1969). Pathophysiology of emotional disorders associated with brain damage. "Handbook of Clinical Neurology" (Eds. Vinken and Bruyn) New York, vol.3, pp. 343-366.

Ross, E. D. and Stewart, R. S. (1987). Pathological display of affect in patients with depression and right frontal brain damage. Journal of Nervous and Mental Disease, 175, $165-172$.

Schiffer, R. B., Herndon, R. M. and Rudick, R.A. (1985). Treatment of pathological laughing and weeping with amitriptyline. New England Journal of Medicine, 312, 14801482.

Sethi, P. K. and Rao, T.S. (1976). Gelastic, quiritarian, and cursive epilepsy. Fournal of Neurology, Neurosurgery and Psychiatry, 39, 823-828.

Sloan, R. L., Brown, K. and Pentland, B. (1991). Fluoxetine as a treatment for emotional lability after brain injury. Brain Injury, in press.

Surridge, D. (1969). An investigation into some psychiatric aspects of multiple sclerosis. British Fournal of Psychiatry, 115, 749-764.

Udaka, F., Yamao, S., Nagata, H., Nakamura, S. and Kemeyama, M. (1984). Pathological laughing and crying treated with levodopa. Archives of Neurology, 41, 1095-1096.

Wilson, S. A. K. (1924). Some problems in neurology-Pathological laughing and crying. Journal of Neurology and Psychopathology, 16, 299-333. 


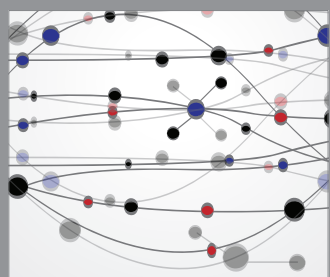

The Scientific World Journal
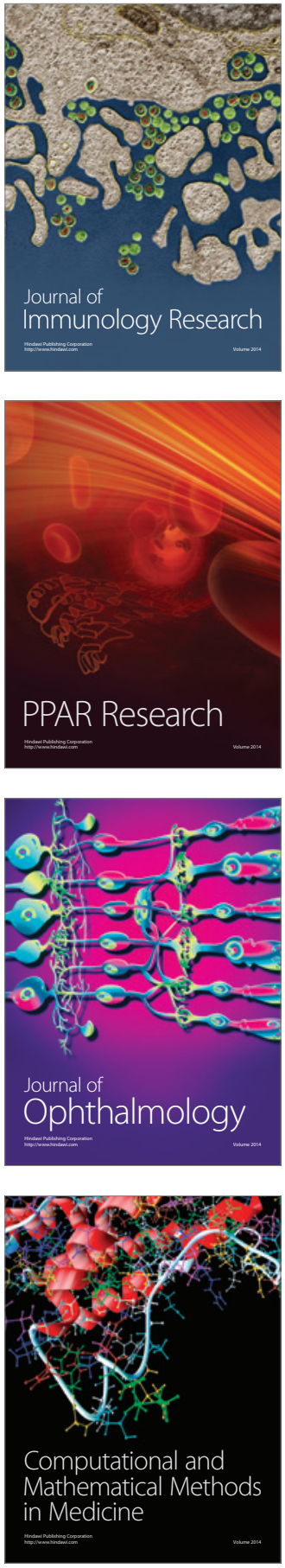

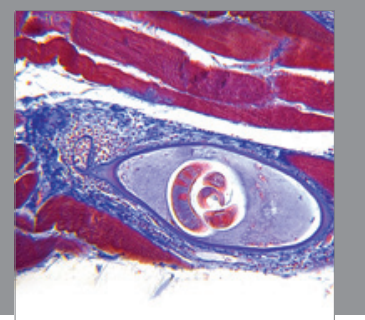

Gastroenterology

Research and Practice
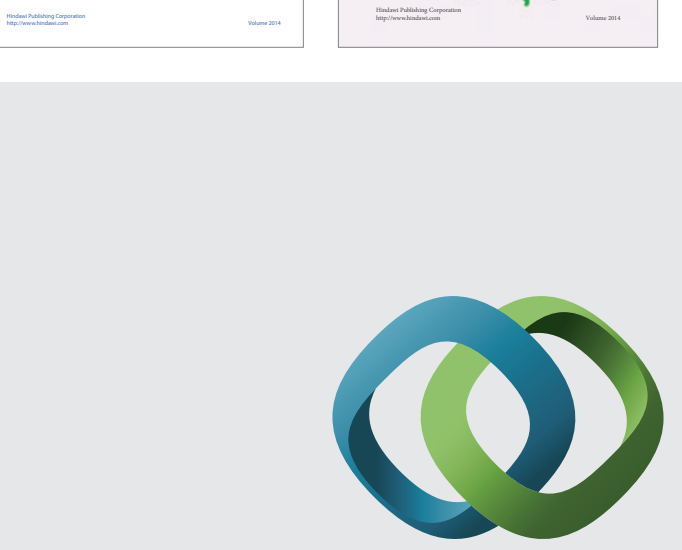

\section{Hindawi}

Submit your manuscripts at

http://www.hindawi.com
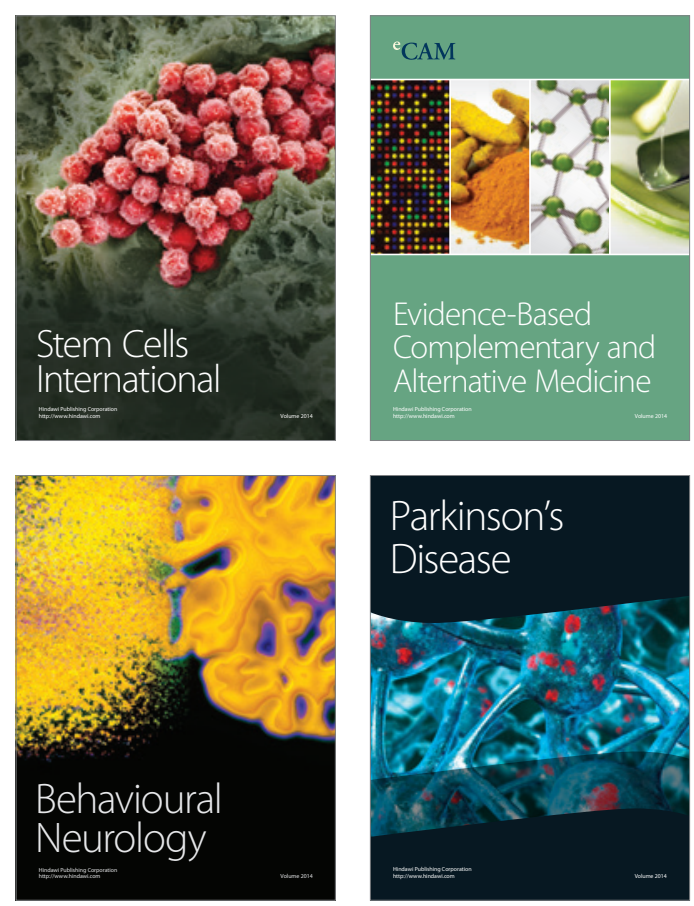

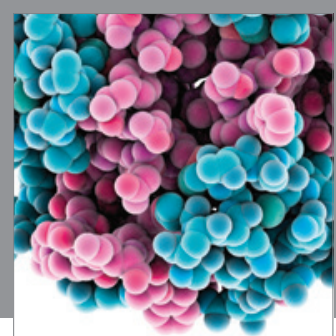

Journal of
Diabetes Research

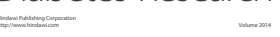

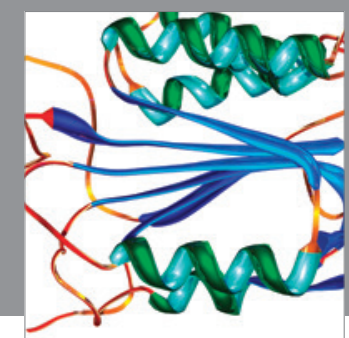

Disease Markers
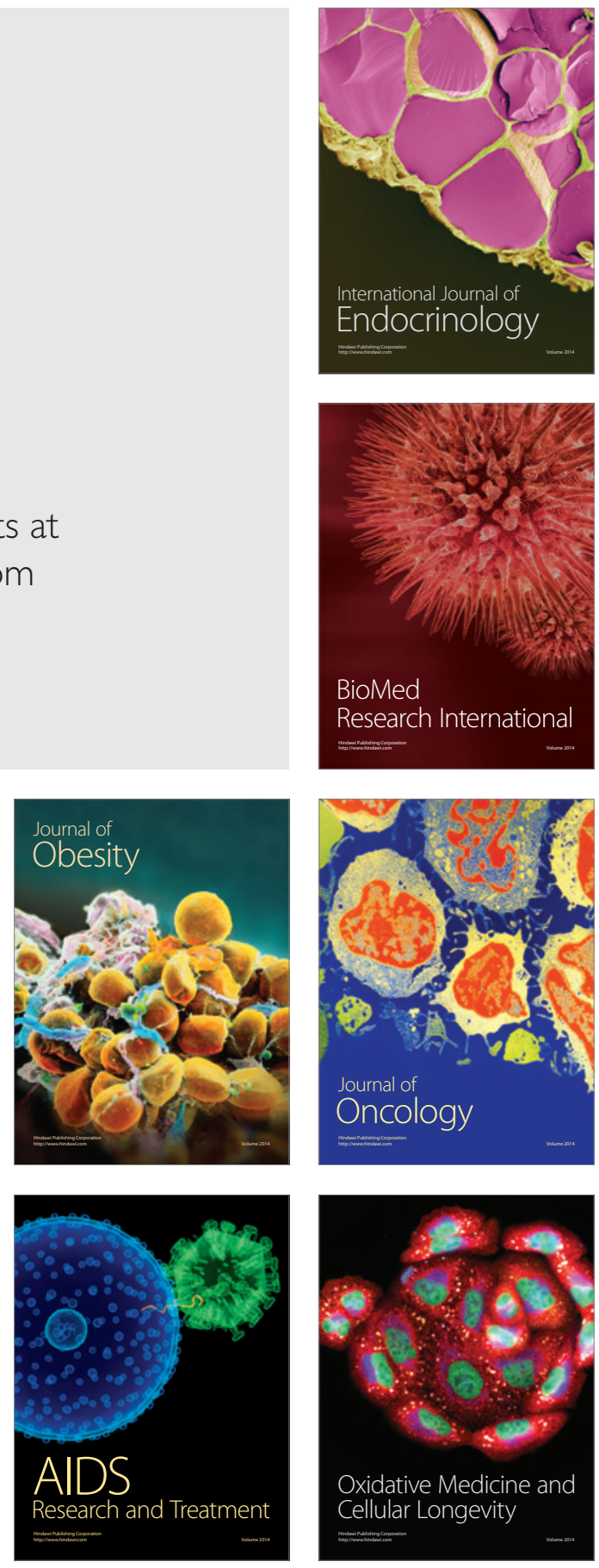